\title{
Participação e conflitos na gestão de escola transformada em Comunidades de Aprendizagem
}

\author{
Edneia Virgínia Pinheiro \\ Celso Luiz Aparecido Conti \\ Universidade Federal de São Carlos
}

\section{Resumo}

Este texto apresenta os resultados de pesquisa realizada em uma escola pública, com o objetivo de compreender as mudanças no seu processo de gestão, no que se refere à participação e aos conflitos, em função da sua transformação em Comunidades de Aprendizagem. Tem-se como referencial básico a teoria da ação comunicativa e a metodologia comunicativa crítica. A investigação indicou mudanças na unidade escolar, desde a implementação da proposta de Comunidades de Aprendizagem, sendo as mais significativas a incorporação do diálogo igualitário nos colegiados da instituição e a compreensão do conflito como ponto de partida para a busca do entendimento, que se estabelece na ação comunicativa.

Palavras-chave: Comunidades de aprendizagem. Gestão democrática da escola. Gestão escolar e participação. Conflito na gestão escolar. 


\section{Participación y conflictos en la gestión de escuela convertida en Comunidades de Aprendizaje}

\section{Resumen}

Este trabajo presenta los resultados de una investigación llevada a cabo en una escuela pública, con el fin de comprender los cambios en su proceso de gestión, por lo que respecta a la participación y a los conflictos, en función de su transformación en Comunidades de Aprendizaje. Se tiene como referencia básica la teoría de la acción comunicativa y la metodología comunicativa crítica. La investigación ha indicado cambios en la unidad escolar, desde la implementación de la propuesta de comunidades de aprendizaje, siendo los más significativos la incorporación del diálogo igualitario en los colegiados de la institución y la comprensión del conflicto como punto de partida para la búsqueda del entendimiento, que se establece en la acción comunicativa.

Palabras clave: Comunidades de aprendizaje. Gestión democrática de la escuela. Gestión escolar y participación. Conflicto en la gestión escolar.

\section{Participation and conflict in management of school transformed in Learning Communities}

\section{Abstract}

This paper presents the results of research conducted in a public school, in order to understand the changes in their management process, with regard to participation and conflicts, due to its transformation into Learning Communities. It has been as a basic reference the theory of communicative action and communicative critical methodology. Research has indicated changes in the school unit, since the implementation of the proposed Learning Communities, the most significant being the incorporation of equal dialogue in the institution's collegiate and understanding of the conflict as a starting point for the search for understanding, which is established in communicative action.

Keywords: Learning Communities. Democratic management of school. School management and participation. Conflict in school management. 


\section{Participation et conflits dans la gestion de l'école transformée en Communauté d'Apprentissage}

\section{Resumé}

Ce texte présente les résultats de la recherche menée dans une école publique, afin de comprendre les changements dans son processus de gestion, en ce qui concerne la participation et les conflits, en raison de sa transformation en Communauté d'Apprentissage. Notre référence de base est la théorie de l'action communicative et la méthodologie communicative critique. La recherche a indiqué des changements dans l'unité scolaire depuis la mise en œuvre de la proposition des Communautés d'Apprentissage, dont les plus importants sont l'incorporation du dialogue égalitaire entre les membres de l'institution et la compréhension du conflit comme un point de départ pour la recherche d'une entente, qui s'établit dans l'action communicative.

Mots-clés : Communautés d'apprentissage. Gestion démocratique de l'école. Gestion scolaire et participation. Conflit dans la gestion scolaire.

\section{Introdução}

Comunidades de Aprendizagem (CA) consistem em uma proposta desenvolvida pelo Centro Especial de Investigação em Teorias e Práticas Superadoras de Desigualdades (CREA), da Universidade de Barcelona/Espanha, e busca minimizar a distância existente entre escola e família, trazendo como fundamento a teoria da ação comunicativa, postulada por Habermas, e a dialogicidade de Paulo Freire. Almejando alcançar a transformação social e cultural da escola, uma CA visa à construção da aprendizagem máxima para todos e todas, a boa convivência na diversidade e a democratização da escola.

A transformação da escola em CA requer o envolvimento da família e da comunidade de entorno, potencializando a participação na gestão e nos processos pedagógicos, de modo que a instituição possa responder satisfatoriamente a suas demandas educativas. Ao escolher se tornar uma CA, a escola opta por convidar a todos/as para integrar seus espaços, trocar conhecimentos, aprender e ensinar simultaneamente. Acredita-se, assim, na construção de um projeto conjunto, sempre visando à potencialização da aprendizagem dos/as alunos/as. A proposta de Comunidades de Aprendizagem, portanto, preconiza que a escola conheça os familiares de seus alunos 
e a comunidade em que está inserida, reconheça seus saberes e com eles dialogue em igualdade.

Ao se tornar uma CA, a escola passa também a ser um espaço no qual se busca a superação dos obstáculos postos ao diálogo, fazendo uso desse para o alcance de soluções que encaminhem para a aprendizagem máxima de todos/as os/as alunos/ as. Nesta proposta, indivíduos com diferentes culturas passam a dialogar entre si em relação de igualdade, prevalecendo as ideias e não as pessoas, em função de suas posições sociais. A proposta de Comunidades de Aprendizagem, assim, supõe que a escola se torne parte da comunidade em que se encontra inserida, democratizando-a, e por ela sendo democratizada.

A mudança ambicionada em Comunidades de Aprendizagem envolve a busca por oferecer uma resposta às demandas da sociedade atual, partindo do compromisso com o processo de transformação social, rumo a uma sociedade mais igualitária e democrática. Buscando o êxito educativo, as CAs apostam em uma sociedade da informação para todos/as, propiciando ao alunado a superação da barreira da exclusão social e educativa.

Tendo em vista estas características de uma unidade escolar transformada em CA, buscamos entender de que forma a participação de toda a comunidade escolar efetivamente ocorria em uma escola municipal de educação básica - EMEB, e de que maneira se manifestavam os conflitos nas relações entre os sujeitos e nos processos de tomada de decisão. Isso porque os processos decisórios devem ocorrer com base no diálogo, que adquire grande importância para que a comunidade chegue ao consenso almejado e, em conjunto, possa agir em busca da transformação da situação de exclusão social e educativa vivida pela população de periferia urbana em uma cidade de médio porte, como é o caso da cidade de São Carlos/SP, onde realizamos este estudo.

Como participação entendemos o modo pelo qual a gestão democrática é garantida, proporcionando maior aproximação entre escola e comunidade, desencadeando um processo coletivo de tomada de decisão e construção de objetivos compartilhados, sobretudo, por meio do diálogo e busca do consenso. O tempo utilizado com o diálogo nunca é perdido, já que por meio da problematização e da crítica ocorre a inserção dos indivíduos na realidade, como sujeitos da transformação. "Toda demora no início significa um tempo ganho em solidez, em segurança, em auto-confiança e interconfiança". (Quaglio, 2009, p. 149)

Em gestão da educação, aqueles que não fazem um esforço no sentido da ampliação do diálogo rejeitam a organização e funcionamento do trabalho nas escolas como situação dialógica de produção do conhecimento. Ao não aceitarem o diálogo comunicativo, não geram "o processo de decisão cooperativa, que assegura o desencadeamento das forças necessárias para promover o desenvolvimento almejado em educação". (ibid., 2009, p.150) 
Visando à superação dos obstáculos postos à participação na vida e na gestão da escola, uma Comunidade de Aprendizagem convida familiares, alunos/as e representantes do entorno para participarem de forma ampla dos colegiados e dos processos de tomada de decisão. Por esta razão, optamos neste estudo por acompanhar o Conselho de Escola e a Comissão Gestora da unidade, por se constituírem em espaços voltados à gestão democrática e, também, por envolverem processos de tomada de decisão.

A Comissão Gestora, presente nas CA, é composta por familiares, professores/as, gestores/as, voluntariado e demais interessados, e consiste na instância responsável pela coordenação das atividades, o que envolve a discussão das formas de dinamização do trabalho na escola. Cabe destacar que tal comissão não requer paridade numérica entre representantes da escola e da comunidade usuária em sua formação.

Por meio do acompanhamento desses colegiados, procuramos identificar e analisar as formas de conflito existentes, assim como os fatores que inibem ou que potencializam sua ocorrência na CA. Buscamos também analisar os processos de tomada de decisão, identificando de que maneira a participação de todos/as e o diálogo igualitário interferem na geração ou inibição dos conflitos.

\section{Pressupostos teóricos de Comunidades de Aprendizagem}

A ação dialógica posta em prática nos processos de tomada de decisão, assim como nas relações cotidianas em Comunidades de Aprendizagem, tem sua base na teoria da ação comunicativa, de Jürgen Habermas.

Habermas (2001) entende que a racionalidade presente nas emissões ou manifestações é medida pelas relações internas entre o conteúdo semântico, as condições de validade e as razões que, se necessárias, podem ser alegadas em favor da validade das emissões ou manifestações, em favor da verdade do enunciado ou da eficácia da regra da ação. Uma manifestação cumpre os pressupostos da racionalidade somente se encarna um saber confiável, mantendo uma relação com o mundo objetivo e resultando acessível a um julgamento objetivo. A racionalidade existente na prática comunicativa remete a diversas formas de argumentação e introduz uma longa excursão sobre a teoria da argumentação, já que a ideia de desempenho discursivo das pretensões de validade ocupa um posto central.

O conceito de ação comunicativa, elaborado por Habermas, refere-se à interação de ao menos dois sujeitos capazes de linguagem e ação que iniciam uma relação interpessoal na qual buscam se entender de forma a poderem coordenar em comum acordo seus planos de ação. O conceito de interpretação se torna central, já que se refere à negociação e definição das situações suscetiveis de consenso. A linguagem, 
neste modelo de ação, é fundamental.

Em última instância, o conceito de racionalidade comunicativa, apresentado pelo autor, possui conotações que remontam à capacidade que uma fala argumentativa detém de reunir e de gerar consenso sem coações. Assim, os diversos participantes superam a subjetividade inicial de seus respectivos pontos de vista e asseguram, graças a convicções racionalmente motivadas, a unidade do mundo objetivo e a intersubjetividade do contexto em que desenvolvem suas vidas, coordenando seus planos de ação.

Supor que o entendimento funcione como mecanismo coordenador da ação significa que os participantes em interação se colocam de acordo acerca da validade de suas emissões ou manifestações, reconhecendo intersubjetivamente as pretensões de validade com que se apresentam uns frente a outros. "Entender-se é um processo de obtenção de um acordo entre sujeitos linguística e interativamente competentes" (Habermas, 2001, p.368). Graças à sua estrutura linguística, um acordo alcançado comunicativamente tem que ser aceito como válido pelos participantes, e não apenas induzido por qualquer motivação externa, sendo assim proposicionalmente diferenciado. A estrutura da argumentação deve excluir toda a forma de coação, se utilizando tão somente do melhor argumento.

Os participantes no processo cooperativo de comunicação estão a serviço da consecução de um consenso sob o qual possam coordenar os planos de ação e realizar suas próprias intenções de ação. O consenso buscado deve se realizar mediante a um acordo racionalmente motivado, ficando a ação comunicativa entre a expectativa do consenso e o risco do dissentimento.

Habermas denuncia que o consenso nem sempre é alcançado na sociedade atual. Há uma crise de consensos oriunda das patologias da comunicação inerentes à estrutura da sociedade capitalista (Gomes, 2007). Segundo Habermas, à medida que as distintas esferas de valor traduzem sua lógica própria em estruturas sociais das correspondentes esferas da vida diferenciadas, o que corresponde a uma diferença entre pretensões de validade no plano da cultura, a sociedade pode ser tomada por tensões entre orientações de ações institucionalizadas, ou seja, por conflitos de ação. (Habermas, 2001)

Quanto maior o grau de racionalidade comunicativa presente em uma comunidade em comunicação, mais amplas se tornam as possibilidades de coordenação das ações sem que se recorra à coerção, de modo a resolver consensualmente os conflitos de ação.

A busca permanente do consenso, pressuposta por Habermas, também pode ser direcionada ao enfrentamento dos desafios educacionais atuais. A consolidação de um projeto educativo voltado ao entendimento racional é a saída encontrada para o alcance de um consenso que visa à superação das divergências e dos conflitos que surgem nas relações sociais. Para isso, a ideia de consenso como fator de coordenação 
da ação dos sujeitos que participam do entendimento deve estar no núcleo desse processo educativo. O entendimento deve buscar um consenso reconhecido sob pretensões de validade e sustentado em dois planos fundamentais: no âmbito das próprias expressões linguísticas e no contexto do mundo da vida. "O termo 'entendimento' tem o significado mínimo de que (ao menos) dois sujeitos linguística e interativamente competentes entendem identicamente uma expressão lingüística". (Habermas, 2001, p.393)

Dessa maneira, a educação pensada enquanto ação orientada para o entendimento passa a focar o estabelecimento da competência comunicativa dos educandos, fortalecendo a crítica sobre as formas de utilização da linguagem. Ao rearticular seu vínculo com a racionalidade comunicativa e com o mundo da vida, a educação restabelece o potencial de racionalidade ofuscado pelo domínio de uma cultura estrategicamente racionalizada. (Gomes, 2007)

Ao entender a sociedade como sistema e como mundo da vida, Habermas (2001) reformula este último conceito para descrever a totalidade de vivências e experiências das pessoas. A tradição cultural partilhada por uma comunidade é constitutiva de um mundo da vida que os membros individuais encontram já interpretado, no que se refere a seu conteúdo. Este mundo da vida intersubjetivamente compartilhado constitui o fundo da ação comunicativa, o horizonte dentro do qual se movem os participantes na interação, quando se referem tematicamente a algo no mundo.

O autor ressalta, porém, a existência de uma crescente sobreposição da racionalidade cognitivo-instrumental sobre o mundo da vida, o que tem culminado em uma colonização desse pelo mundo sistêmico. Com a presença da racionalidade cognitivoinstrumental estruturada de forma hegemônica no mundo, é dirimida a possibilidade de formação de consensos fundados em uma racionalidade comunicativa, que contemplem as dimensões do mundo da vida.

De acordo com Pinto (1996), a colonização do mundo da vida se evidencia na educação sob a forma da excessiva burocratização e do formalismo exacerbado. Embora tanto escola quanto família se encontrem inseridas na esfera do mundo da vida, esta burocratização, que se enquadra em um processo mais amplo, que ocorre em toda a sociedade, leva à sua colonização pela racionalidade sistêmica.

Como resultado desse processo de colonização do mundo da vida no cotidiano escolar encontra-se a passividade que é observada em professores, pais e alunos. A reconquista dos espaços que foram tomados pelo sistema é apontada pelo autor (Ibidem) como única saída para que as patologias oriundas de sua colonização sejam sanadas.

Segundo Gomes (2007), a tarefa da educação deve ser orientada pela reversão da colonização do mundo da vida por meio da ampliação do uso comunicativo da linguagem, fundamentado na possibilidade do consenso a ser alcançado 
comunicativamente. Órgãos como os conselhos de escola, de acordo com Pinto (1996), podem ser entendidos como uma tentativa do mundo da vida de resgatar seus domínios, tomados pela burocratização da escola.

Dessa forma, sobressai a necessidade de importantes mudanças no que concerne à gestão da educação, que deve envolver processos comunicativos de busca de consensos, alcançados por meio do entendimento. Como na ação comunicativa as decisões são tomadas de acordo com o melhor argumento (democracia deliberativa), e não por maioria de votos (democracia representativa), é dirimida a possibilidade de que o segmento escolar mantenha o controle do colegiado, com independência da posição de pais e alunos.

\section{Método e procedimentos de pesquisa}

O estudo foi desenvolvido tendo como referência a metodologia comunicativa crítica, fundamentada na teoria da ação comunicativade Habermas, que concebe a análise da realidade sob um duplo prisma: o dos sistemas e suas estruturas, e o do mundo da vida e a agência humana. A ênfase é posta nas interações ocorridas na vida social, uma vez que aí se encontram as dimensões que levam à exclusão e à inclusão, preconizando a transformação da realidade social.

Comunicação intersubjetiva e reflexão crítica constituem as bases da metodologia comunicativa crítica, que é comunicativa porque supera a dicotomia objeto/sujeito mediante à categoria intersubjetividade, e é crítica porque parte da capacidade de reflexão e de autorreflexão das pessoas, almejando a geração de conhecimentos que contribuam para a superação de desigualdades sociais. (Gómez et al., 2006)

Nesta perspectiva, entende-se que a realidade natural existe no mundo externo de forma objetiva, independente da mente dos sujeitos; a realidade social, no entanto, é construída por meio das definições dadas pelos atores mediante as interações, partindo da capacidade de interpretação e da autocompreensão que têm indivíduos e sociedades.

A perspectiva comunicativa crítica baseia sua validade no consenso permanente, nunca fruto de coação ou imposição, mas sim comunicativamente alcançado, tendo como eixo central o diálogo. Os significados emergem do consenso obtido pela interação humana com base nas pretensões de validade.

Em uma pesquisa baseada na metodologia comunicativa crítica, os pressupostos ontológicos dos investigadores não são mais complexos que os que devem ser atribuídos aos atores sociais que participam do estudo, pois, segundo o modelo comunicativo de ação, o agente dispõe de uma competência de interpretação 
igualmente complexa à do observador. $\mathrm{O}$ investigador, assim, tem a responsabilidade de incorporar ao diálogo os conhecimentos disponíveis na sociedade científica, conhecimentos estes que podem ser refutados, transformados, ampliados ou complementados pelos argumentos empregados pelas pessoas investigadas ao serem confrontados com os conhecimentos e a prática do mundo da vida dessas pessoas (Gómez et al., 2006). A metodologia comunicativa crítica defende, portanto, a interpretação conjunta da realidade social, feita tanto pelos investigadores quanto pelas pessoas investigadas, em base de igualdade. (Elboj et al., 2002)

Por esta razão, esta investigação contou, em todas as suas etapas, com a participação ativa da comunidade escolar. Permanecemos em constante diálogo com gestores/as, professores/as, alunado, comunidade de entorno e familiares na busca de respostas às questões inicialmente levantadas, processo este estabelecido, sobretudo, nas reuniões dos colegiados da escola.

Os dados, eminentemente qualitativos, foram coletados por meio de técnicas voltadas a um maior aprofundamento na relação pesquisadores/sujeitos pesquisados, característica que as diferencia de outras técnicas semelhantes e mais tradicionais no campo da investigação social. Para tanto, os procedimentos abarcaram entrevistas em profundidade e observações comunicativas, estas últimas realizadas durante as reuniões dos colegiados da escola.

As entrevistas em profundidade consistem em encontros com o/a participante, em lugares de seu cotidiano, para falar sobre aspectos desse cotidiano. As análises e compreensões vão sendo construídas em conjunto pelo/a pesquisador/a e pelo/a participante, que conhece o tema e as intenções da investigação desde seu início. A entrevista, transcrita, é revisada pelo/a entrevistado/a e a análise dos dados é com ele/a discutida, o que permite que pesquisador/a e participante se comprometam com a compreensão do tema investigado.

Ao longo do desenvolvimento deste estudo, buscamos analisar as informações obtidas a partir da leitura exaustiva das entrevistas. Estas foram analisadas em vários momentos e em diferentes âmbitos: inicialmente pelos pesquisadores de forma individual, e posteriormente, em interação com os participantes da pesquisa, para a averiguação do entendimento efetuado pelos pesquisadores nos diversos momentos da entrevista em profundidade, dialogando sobre seu conteúdo, com vistas a uma interpretação comum. Estes procedimentos metodológicos tiveram como participantes: a diretora da unidade, a assistente de direção, uma professora (que atuava como coordenadora pedagógica nos últimos dois anos) e um familiar.

Com o objetivo de preservar a identidade das pessoas entrevistadas, utilizamos siglas para identificar cada uma das falas expostas na apresentação dos dados. No quadro a seguir apresentamos as siglas utilizadas, que trazem a identificação do entrevistado, precedida da modalidade de coleta de dados (entrevista) e do número da entrevista em que a fala destacada se localiza (Ex: E1P = Entrevista 1, Professor). 
Quadro 1: Siglas de identificação dos entrevistados

\begin{tabular}{|l|l|}
\hline Entrevistado/a & Sigla de identificação \\
\hline Assistente de Direção & E1AD \\
\hline Coordenadora Pedagógica & E1CP \\
\hline Diretora & E1D \\
\hline Familiar & E1F \\
\hline
\end{tabular}

Fonte: Dados da pesquisa.

Já as observações comunicativas, também utilizadas para coleta de dados nesta pesquisa, devem ocorrer no ambiente da investigação, o que permite ao pesquisador presenciar o fenômeno em estudo de forma direta. O que diferencia a observação comunicativa das demais observações, no entanto, é sua natureza participativa, que permite ao investigador aproximar-se de forma mais intensa das pessoas e grupos estudados, possibilitando também que conheça a realidade social em que está implicado. Esta técnica tem por objetivo dispor de registros narrativos da forma mais exata e completa possível. Outro fator que a torna específica perante os demais tipos de observação é o fato de que sua interpretação também se dá de maneira intersubjetiva. Há um diálogo antes da observação, em que são decididos os seus objetivos, e outro após a observação, em que se valida os resultados obtidos em um diálogo intersubjetivo (Gómez et al., 2006). Especificamente neste estudo, as observações comunicativas ocorreram ao longo de 14 meses, totalizando 20 (vinte) observações realizadas predominantemente nos ambientes voltados à participação na gestão da escola e processos de tomada de decisão.

Após a realização dos procedimentos qualitativos de coleta de dados, o processo de análise englobou a busca por dois tipos de dimensões, sempre presentes na realidade: dimensões que produzem exclusões ou obstáculos, ou seja, que se configuram enquanto barreiras que impedem a efetivação de maior igualdade social, e dimensões transformadoras, que mostram formas de superar estas barreiras. A distribuição dos dados se deu conforme o quadro a seguir:

Quadro 2: exemplo de nível básico de análise - categorias e dimensões

\begin{tabular}{llll}
\hline Dimensões exclusoras/obstáculos & Sistema & Mundo da vida \\
\hline Dimensões transformadoras & 1 & 2 \\
\hline
\end{tabular}

Fonte: Gómez et al., 2006, p.103. 
Neste estudo, no entanto, optamos por substituir as categorias sistema e mundo da vida pelas temáticas de interesse desta pesquisa, que foram identificadas nas entrevistas em profundidade e observações comunicativas. Estas temáticas foram cruzadas com as dimensões transformadora e exclusora, dando origem aos quadros de análise que integram a investigação. Em uma investigação comunicativa crítica, a presença dessas dimensões configura um primeiro passo para a concretização de ações com vistas à superação dos obstáculos existentes na realidade estudada.

\section{A pesquisa na unidade escolar transformada em Comunidades de Aprendizagem e o resultado da análise da participação e dos conflitos na gestão}

No ambiente escolar, a problematização das relações com o mundo e sua consequente transformação devem ocorrer por meio da participação de forma igualitária em todos os seus ambientes, incluindo os âmbitos de tomada de decisão relacionados à gestão, como Conselho de Escola e, em Comunidades de Aprendizagem, também a Comissão Gestora.

É por meio da efetiva participação que a ação transformadora ocorre:

Participação implica que todos os membros da comunidade tenham acesso à tomada de decisões, a como se estrutura administrativa e curricularmente a educação. Baseando-se em que as proposições que realizem cada um deles devem estar sempre submetidas à crítica por parte dos outros membros que também participam da tomada de decisões. (Ferrada, 2001, p.103)

A incorporação da racionalidade comunicativa na educação, segundo Ferrada (2001), implica na aceitação dos conflitos mediante pretensões de validade.

A superação desses conflitos deve ocorrer por meio de acordos racionalmente alcançados, que dão origem ao consenso como fator de coordenação da ação dos sujeitos que participam do entendimento comunicativo. Por esta razão, em Comunidades de Aprendizagem, o dissenso deixa de representar falta de controle sobre o mundo objetivo, já que por meio da linguagem e da ação busca-se a solução para ele. O dissenso, segundo Ferrada (2001), adquire uma qualidade positiva, "como ponto de início da busca do entendimento" (p.23). Isso porque as interferências e o dissenso favorecem o enriquecimento da ação, em função das diversas opiniões e interesses dos diferentes componentes da comunidade envolvida, que são suscetíveis de crítica e modificáveis durante a ação. O dissenso (ou conflito), assim, não é temido, mas entendido como próprio de uma comunidade submetida a um amplo e profundo processo de comunicação. 
Durante o período em que foram realizadas observações comunicativas nos colegiados da escola transformada em CA, foram acompanhados os encontros mensais do Conselho de Escola da unidade, que contava com a participação da diretora, de professoras PIII (Educação de Jovens e Adultos/EJA), de funcionários/as, pais e/ou responsáveis e, como presidente do Conselho, uma professora PII (séries iniciais do ensino fundamental).

Foram acompanhadas também as reuniões da Comissão Gestora, que ocorreram quinzenalmente, contando com a participação de todos aqueles que manifestaram interesse em acompanhar e compartilhar o processo de gestão. Durante o período de observação, a comissão contava com a participação de gestoras da unidade, de professores/as e pais, representantes da associação de moradores, assistente social de uma empresa multinacional presente no bairro e representantes da Unidade de Saúde da Família (USF), além da gestora comunitária, responsável pelo desenvolvimento do projeto municipal "Escola Nossa", aos finais de semana, na unidade.

As observações comunicativas permitiram a constatação de que a dinâmica já adotada pelas pessoas que participavam da Comissão Gestora tinha a busca pelo consenso como fator de coordenação da ação. Foi observada também a presença da racionalidade comunicativa, manifesta por meio dos procedimentos estabelecidos pelo uso da argumentação. O consenso, nestas reuniões, se mostrou fundamental para o desenvolvimento da competência comunicativa entre os sujeitos, atuando como critério de validação do pensar e do agir. Propiciava-se, assim, não somente que familiares e profissionais da escola pudessem problematizar suas relações com o mundo, mas também voluntários/as, moradores/as do bairro, representantes de indústrias locais, comerciantes e demais representantes da comunidade pudessem somar forças e juntos refletirem, reivindicarem, exigirem, posicionarem-se, agirem e transformarem. Garantia-se, dessa forma, que a Comissão Gestora não consistisse em mais um órgão burocrático vinculado ao sistema, mas em manifestação do mundo da vida na busca por reconquistar seu espaço.

No entanto, convém dizer que foi comum identificar na fala dos entrevistados uma baixa participação de pais e familiares nos colegiados, conforme pode ser observado no quadro a seguir, que apresenta as dimensões transformadora e exclusora vinculadas à participação: 


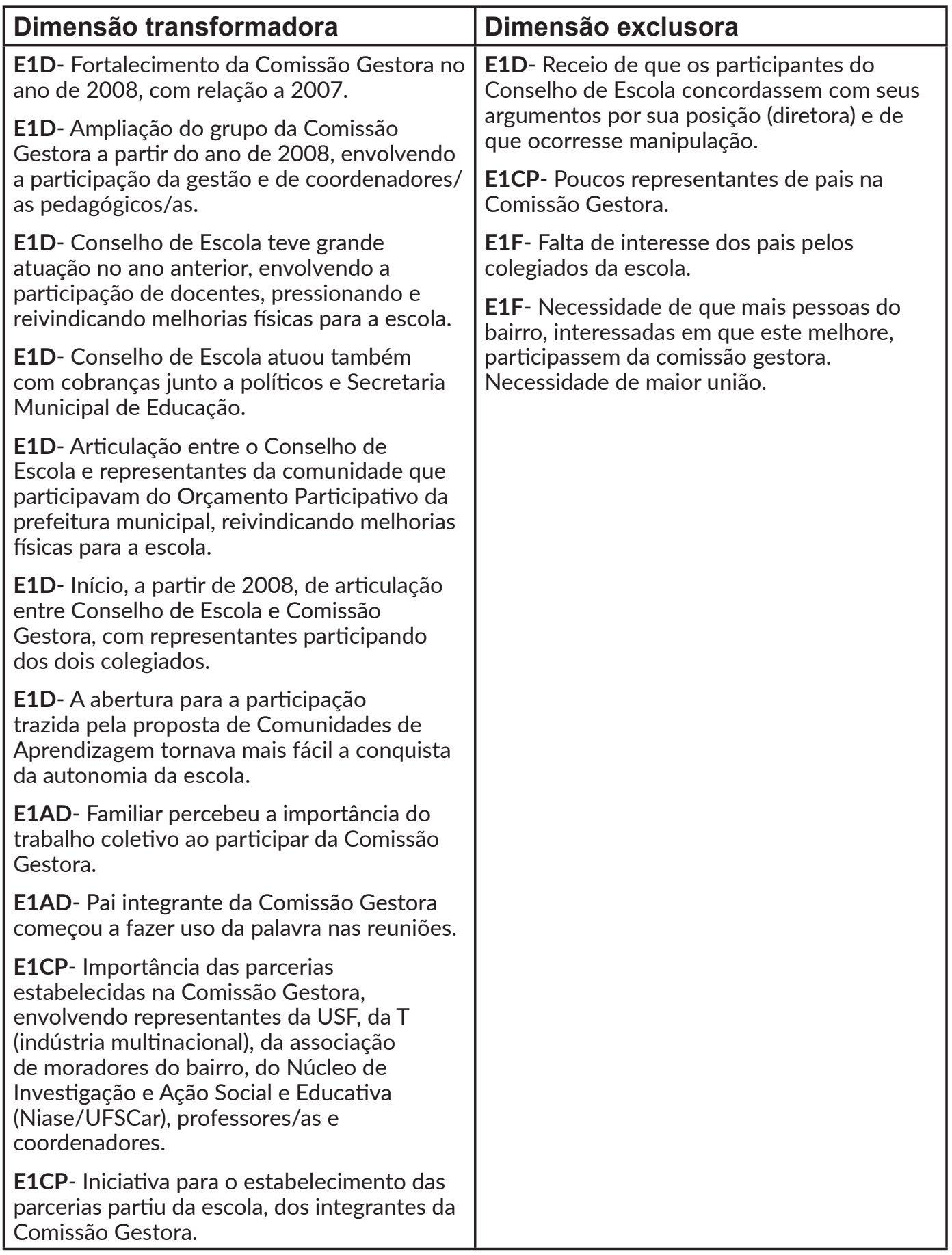

Fonte: Dados da pesquisa. 
Apesar do reconhecimento de todos/as os/as entrevistados quanto ao fortalecimento dos colegiados nos últimos anos, a coordenadora (E1CP) e o familiar (E1F) apontaram a necessidade de uma participação mais intensa de representantes da comunidade de entorno para o alcance definitivo da articulação e colaboração entre esta e a escola.

A participação da comunidade nos processos de tomada de decisão era entendida pela coordenação da escola como importante forma de trazer os familiares para sua práxis, para que refletissem e agissem juntos, em colaboração. No decorrer da pesquisa fezse notório que, aos poucos, familiares e comunidade iam deixando de fazer parte apenas das reflexões ocorridas nos colegiados, passando também a agir de forma conjunta. Os entrevistados destacaram a nova significação que a participação adquire quando a comunidade se percebe como capaz de refletir, agir, e assim transformar.

Diante da importância da participação de todos, alguns entrevistados argumentavam que a escola deveria ainda tomar novas medidas, buscando maior aproximação com a comunidade, cientes da força que o entendimento entre escola e entorno poderia representar na coordenação dos planos de ação e busca da transformação almejada por todos/as.

Como nos mostra Pinto (1996), ao focar a participação de familiares nos conselhos escolares tendo como referência a teoria da ação comunicativa, a omissão dos pais e sua não participação pode ser entendida como consequência da colonização do mundo da vida pela racionalidade sistêmica e seus meios diretores dinheiro e poder:

À luz da teoria da ação comunicativa, esta omissão de assumir o papel de cidadão, este medo de participar, de se expor, não pode ser entendido como fruto de um mero ato de vontade do indivíduo, mas como consequência de um processo mais amplo de colonização do mundo da vida pelos meios diretores dinheiro e poder, que atuam tanto a nível da reprodução material do mundo da vida como no âmbito da reprodução de suas estruturas simbólicas (cultura, sociedade e pessoa). (Pinto, 1996, p.151)

Esse contexto, todavia, não deve ser dado como definitivo. A descolonização do mundo da vida, por meio da racionalidade comunicativa, a ser viabilizada também pela participação nos colegiados e processos de tomada de decisão, deve continuar a ser buscada pela escola. Tentativas podem ser empreendidas por meio de uma maior adequação dos horários das reuniões aos horários disponíveis pelos familiares, ouvindo suas sugestões, assim como procurando conhecer as razões pelas quais têm participado pouco ou não têm participado. Buscar compreender os interesses dos familiares e da comunidade, assim como aquilo que gostariam de ajudar a viabilizar, pode consistir em mais uma maneira de trazer a comunidade para a escola, fomentando a participação nos processos de reflexão, entendimento e tomada de decisão.

Além da articulação entre escola e comunidade, vinha-se buscando a articulação entre os dois colegiados da unidade. Dessa forma, discussões, reflexões e argumentos 
poderiam ser compartilhados entre todos/as. As análises realizadas pelos/as integrantes dos colegiados apontaram um crescente fortalecimento tanto do Conselho de Escola quanto da Comissão Gestora, ao longo dos últimos anos. A viabilização de melhoras na aprendizagem, no funcionamento da escola e em sua abertura para a comunidade eram os grandes objetivos da unidade, consistindo em alvos de constantes reflexões nestes âmbitos voltados à tomada de decisão.

O diálogo mostrava-se elemento fundamental neste processo, já que por meio dele se estabelecem os processos de colaboração, visando à construção de um mundo comum. Com todas as falas confrontadas na interlocução, cria-se a possibilidade de estabelecimento de novas compreensões e alcance do consenso, em busca da superação dos obstáculos encontrados, possibilitando a implementação de ações conjuntas.

Outro fator mencionado pelos entrevistados refere-se ao reconhecimento da existência de conflitos nas relações entre as pessoas presentes na escola, conforme dados identificados nas análises: 
Quadro 4: Conflitos e processos de tomada de decisão

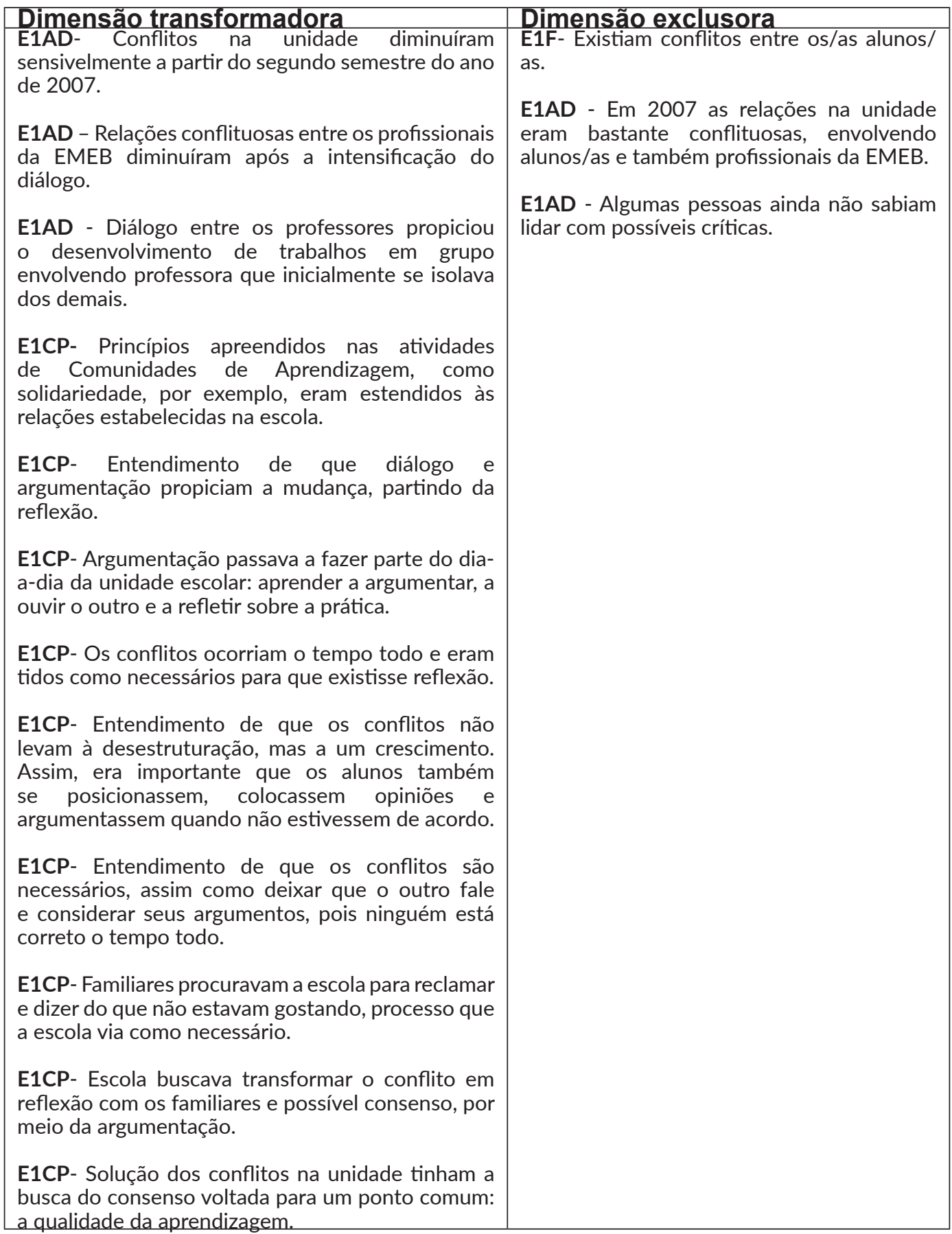

Fonte: Dados da pesquisa. 
$\mathrm{Na}$ análise realizada pela coordenadora pedagógica, os conflitos já não eram mais dotados de caráter negativo ou entendidos como processo a ser evitado. Isto porque as soluções para estes conflitos eram buscadas por intermédio do entendimento comunicativo e de acordos realizados no coletivo.

Dessa maneira, entendeu-se que o conflito consiste em elemento propulsor da reflexão sobre ações e entendimentos individuais e/ou concernentes à comunidade. Partindo do conflito, chega-se ao enriquecimento das ações, ao se levar em consideração opiniões e argumentos das diversas pessoas envolvidas no diálogo, suscetíveis de crítica e modificáveis durante a ação.

Como destacado por Flecha (1997), "A ação dialógica necessita tanto do consenso quanto do dissenso. Todas as experiências e teorias afins valorizam a necessidade do primeiro. Porém, muitas insistem na importância do segundo" (p.79). Quando o diálogo igualitário se faz ausente, a inexistência de conflitos nem sempre é sinônimo da existência de consenso. Ao contrário, este aparente consenso pode ser fruto de imposição, resultante das relações de poder: "Muitas vezes o diálogo aberto é substituído por um consenso imposto pela posição hierárquica ou pelo status superior do falante. Esse muro pode ser derrubado por meio do dissenso apoiado em seus melhores argumentos" (Flecha, 1997, p.79). O conflito, assim, adquire a característica de superação das relações de poder, que são substituídas pelo entendimento nos processos decisórios, tendo como meio o diálogo igualitário e a argumentação. Dessa forma, o conflito torna-se elemento necessário. Desconsiderar ou reprimir a existência do conflito adquire características antidialógicas, de imposição e uso do poder.

\section{Considerações finais}

Comunidades de Aprendizagem acredita na ideia de que todas e todos têm a capacidade de transformar seus contextos por meio do diálogo intersubjetivo, superando situações de desigualdade e exclusão. Não ignora, destarte, as diferenças existentes entre as pessoas, mas acredita que estas não consistem em barreiras para que elas alcancem o entendimento e lutem por objetivos que são comuns (Elboj et al., 2002). Refletindo juntos, em comunicação, e questionando o mundo, homens e mulheres deixam de se adequar a ele, tornando-se mais atuantes, humanizando-se e vendo-se como capazes de criar e agir. (Freire, 1980)

A construção comunicativa de significados, mediante interação, consiste em meio para que as pessoas conheçam a realidade, a compreendam e a transformem, fazendo uso da intersubjetividade, da reflexão e das teorias das pessoas que integram a realidade social que almejam transformar. $O$ entendimento, alcançado pelas pessoas em um processo de recíproco convencimento, com base em pretensões de validade suscetíveis de crítica, leva os diversos participantes à coordenação das ações, 
motivados por razões. Dessa forma, as pessoas enfrentam as situações que tem se tornado problemáticas por meio da ação comunicativa, com a tomada de postura de afirmação ou negação frente a pretensões de validade dos sujeitos, chegando a um acordo. Este acordo deve, necessariamente, ser aceito como válido pelos participantes e nunca imposto por motivação externa. (Habermas, 2001)

Buscando este entendimento, a superação das relações de poder e a democratização dos processos decisórios, a CA tem se dedicado à ampliação da participação de representantes de professores/as, familiares e comunidade de entorno nos colegiados, propiciando a todos/as o direito à palavra, pela qual o homem pronuncia o mundo e também o transforma (Freire, 1980). Assim, almeja que todos os sujeitos sejam capazes de problematizar suas relações com o mundo e lutar pelas mudanças necessárias.

A participação, essencial para a efetivação da gestão democrática nas escolas, não é algo que possa ser imposto, mas sim alcançado de maneira gradual, por meio do convencimento das pessoas, ao se verem articuladas com uma proposta entendida como viável e que produza resultados. A participação de todos/os na solução dos problemas da unidade de ensino impulsiona e encoraja a equipe escolar, familiares e alunos/as, integrando-os à escola e fazendo com que se sintam parte do processo, conferindo mais significado a suas ações e levando-os a assumirem responsabilidades nos procedimentos de tomada de decisão, aferindo maior importância à escola e ao que nela é desenvolvido. Logo, escola e comunidade se aproximam, dando origem a um processo coletivo de tomada de decisão que envolve a determinação de objetivos construídos e compartilhados por meio do diálogo e do consenso. Por meio da participação é que são formados cidadãos conscientes, política e socialmente participativos e voltados à transformação social.

Sabemos, entretanto, que o entendimento comunicativo nem sempre se faz presente nas relações entre os sujeitos. A coordenação das ações, dada por meio de reivindicação de validade às pretensões apresentadas, passa pelo reconhecimento dessas no espaço público das razões. Quando o consenso não é alcançado nos três planos compreendidos na intenção comunicativa do falante - verdade, correção normativa e veracidade - surge o que Habermas (2001) identifica como distorção na comunicação, ocasionando os conflitos.

Os conflitos que se estabelecem nas sociedades modernas colocam em questão a capacidade de integração que compõe a unidade do mundo da vida. Compreendemos, porém, que a presença de um maior grau de racionalidade comunicativa em uma comunidade em comunicação amplia a possibilidade de coordenação dos planos de ação, sem que ocorra coerção, resolvendo os conflitos por meio do consenso.

Isso posto, o consenso deve estar presente no núcleo do processo educativo, nas relações cotidianas e na sala de aula, assim como nos processos de tomada de decisão da CA. Reconhecido sob pretensões de validade suscetíveis de crítica, deve se sustentar no âmbito das próprias expressões linguísticas e no contexto do mundo 
da vida. Por meio do consenso, a escola visa à recuperação de seu vínculo com a racionalidade comunicativa, progressivamente tomada pela racionalidade cognitivoinstrumental, própria do sistema, que leva à colonização do mundo da vida.

A saída apontada para a superação das patologias oriundas dessa colonização consiste na reconquista, por parte do mundo da vida, dos espaços que lhe foram tomados pelo sistema. Para que isso se dê, torna-se necessária a consolidação de mudanças profundas na gestão da educação, voltadas para processos comunicativos de busca do entendimento. Como âmbito onde ocorrem os processos de produção e transmissão cultural, próprios do mundo da vida, a escola deve promover mudanças nos mecanismos de decisão, levando em conta a participação de todos aqueles que sofrerão os efeitos de sua ação (familiares, professores/as, alunos/as, gestores/as, comunidade de entorno).

Diante da presença de diferentes pessoas, com diferentes culturas e diferentes conhecimentos na escola, torna-se essencial que a comunidade em comunicação alcance acordos, estabelecidos por meio da racionalidade comunicativa, para que possam atingir seus objetivos. O diálogo cumpre a função de coordenar os planos de ação entre os agentes formativos, permitindo que passem a planejar e executar juntos o processo de educação escolar.

No caso da escola pesquisada, transformada em Comunidades de Aprendizagem, houve avanços no que condiz à gestão, conforme já mencionado. Ainda que houvesse dificuldade de participação, em termos numéricos, ela se dava de maneira intensa. Em conjunto, professores/as, familiares, gestores/as, coordenadores/as pedagógicos/as, representantes de órgãos públicos (Unidade de Saúde da Família/ USF e também da Secretaria Municipal de Educação) e empresas particulares, representantes da associação de moradores do bairro, voluntários/as, representantes do legislativo municipal, etc. possibilitaram que fossem colocadas em prática ações com vistas à ampliação das parcerias estabelecidas pela unidade escolar, visando ao desenvolvimento das atividades de CA e outras tantas, de interesse da escola.

Assim, em parte pela integração da Comissão Gestora e do Conselho Escolar, houve uma boa articulação da comunidade escolar com a comunidade de entorno, o que fortaleceu a ação da escola e favoreceu a expansão da pauta de debates, nos colegiados, de modo que os assuntos circunscritos apenas ao âmbito interno vinham, cada vez mais, acompanhados por outros, externos, mas relacionados à vida da unidade escolar. Em certa medida, é como se escola se tornasse bairro, e o bairro se tornasse escola. Tudo isso foi se dando porque todos os sujeitos envolvidos iam conquistando o direito legítimo de fala, o que por vezes produzia conflitos, a partir dos quais o movimento se dava na direção da ação transformadora, ou seja, estabeleceuse, pouco a pouco, uma dinâmica de maior participação, de maior legitimação das falas e, por conseguinte, de busca de ações transformadoras da realidade concreta, com base em consensos produzidos, ainda que provisórios. 


\section{Referências}

ELBOJ, Carmen; PUIGDELLÍVOL, Ignasi; SOLER, Marta Gallart; VALLS, Rosa. Comunidades de aprendizaje: transformar la educación. Barcelona: Graó, 2002.

FERRADA, Dona. Currículum crítico comunicativo. Barcelona: El Roure, 2001.

FLECHA, Ramón. Compartiendo palabras: El aprendizaje de las personas adultas a través do diálogo. Barcelona: Paidós, 1997.

FREIRE, Paulo. Pedagogia do Oprimido. $8^{a}$ edição. São Paulo: Editora Paz e Terra, 1980.

GOMES, Luiz Roberto. Educação e consenso em Habermas. Campinas: Editora Alínea, 2007.

GÓMEZ, Jesús.; LATORRE, Antonio.; SÁNCHEZ, Montse.; FLECHA, Ramón. Metodología comunicativa crítica. Barcelona: El Roure, 2006.

HABERMAS, Jürgen. Teoria de la Acción Comunicativa. Vol. I. Racionalidad de la acción y racionalización social. Madrid: Taurus, 2001.

PINTO, José Marcelino de Rezende. Administração e liberdade: um estudo do conselho de escola à luz da teoria da ação comunicativa de Jürgen Habermas. Rio de Janeiro: Tempo Brasileiro, 1996.

QUAGLIO, Paschoal. Gestão da educação e dialogicidade problematizadora. In: Revista Brasileira de Política e Administração da educação - v. 25, n 1- jan/abr, 2009.

Recebido em maio de 2016

Aceito em julho de 2017

Edneia Virgínia Pinheiro é Doutoranda e mestre em Educação pela Universidade Federal de São Carlos, Linha Educação Escolar: Teorias e Práticas. Pedagoga no Instituto Federal de São Paulo. Email: edneiavpinheiro@hotmail.com

Celso Luiz Aparecido Conti é Professor Doutor Associado do Departamento de Educação e do Programa de Pós-Graduação em Educação da Universidade Federal de São Carlos. Email: celsocon@ufscar.br 